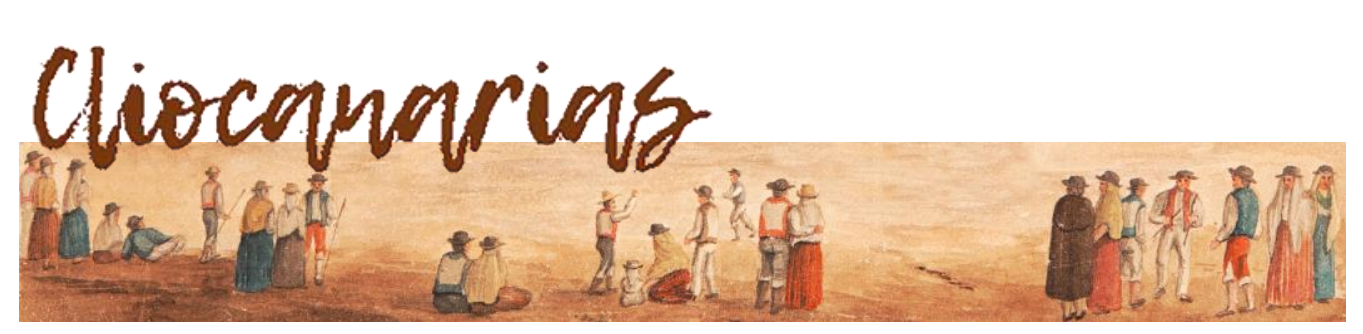

ISSN 2695-4494

https://doi.org/10.53335/cliocanarias.2021.3.05

\title{
LA CUESTIÓN DE LOS TARAPAQUEÑOS PERUANOS: CHILENIZACIÓN Y NACIÓN EN LA ANTIGUA JURISDICCIÓN DE TARAPACÁ (1918-1922)
}

THE QUESTION OF THE PERUVIAN TARAPAQUEÑOS: CHILEANIZATION AND NATION IN THE OLD JURISDICTION OF TARAPACÁ (1918-1922)

René Patricio AGUILERA BARRAZA*

RESUMEN: Este artículo, a partir de información documental, aborda el clima de violencia compulsivo desplegado contra los tarapaqueños peruanos, entre 1918 y 1922. Contexto de xenofobia extrema que en sus primeros dos años tendrá el papel clave de las ligas patrióticas, cuyo objetivo fue anular y excluir la presencia peruana que seguia obstaculizando la consolidación del proyecto nacional de los conquistadores en suelo tarapaqueño, después de 35 años de la firma del Tratado de Paz y Amistad suscrito por Chile y Perú por el que fue cedida legalmente a soberanía chilena la jurisdicción de Tarapacá.

PALABRAS CLAVE: chilenización, desperuanización, nacionalismo, tarapaqueños, violencia

ABSTRACT: This article, based on documentary information, addresses the climate of compulsive violence deployed against the Peruvian Tarapaqueños, between 1918 and 1922. A context of extreme xenophobia that in its first two years will play the key role of the patriotic leagues whose objective was to annul and exclude the Peruvian presence that continued to hinder the consolidation of the national project of the conquerors on Tarapaca soil, 35 years after the signing of the Treaty of Peace and Friendship signed by Chile and Peru, by which the jurisdiction of Tarapacá was legally ceded to Chilean sovereignty.

KEY WORDS: chilenization, deperuanization, nationalism, tarapaqueños, violence

* Profesor de la Universidad de Santo Tomás de Chile, Arica. C. e.: reneaguilera912@hotmail.com 


\section{Introducción}

El estudio aborda el clima de nacionalismo compulsivo y racista desplegado en suelo tarapaqueño ${ }^{1}$, entre 1918 y 1922. Vale la pena agregar que los hechos de violencia en Tarapacá comenzaron años antes, con la matanza obrera de la escuela Santa Maria en 1907, hecho que marcará lentamente el cambio de actitud en las autoridades chilenas para imponer la soberanía nacional en términos políticos y simbólicos ${ }^{2}$ en la ex región peruana de Tarapacá. Se pasará de una conducta de aceptar la composición cosmopolita y pluriétnica de la población, entre 1883 y 1910, a una actitud de racismo y xenofobia compulsiva entre 1911 y 1929, orientada a homogeneizar el territorio ganado en la guerra del Salitre (1879-1883) bajo el matiz nacional de lo chileno, consintiendo para ello la violencia compulsiva contra los tarapaqueños peruanos. Fue 1911 el primer momento en que las Ligas Patrióticas desplegaron sus acciones de hostilidad y violencia contra el peruano y simpatizantes por la causa peruana, causando que muchos tarapaqueños ese año decidieran partir a Perú ${ }^{3}$.

El período histórico descrito por este artículo (1918 a 1922) encarna un segundo momento de violencia compulsiva, que en sus dos primeros años tendrá como actor protagónico de la animadversión contra el peruano a las Ligas $\mathrm{Pa}-$ trióticas, que buscaran anular y excluir la presencia peruana que continuaba obstaculizando la construcción del proyecto nación chileno en la región de Tarapacá, después de 35 años de cedida a Chile con la firma del Tratado de Ancón suscrito por los gobiernos chileno y peruano en octubre de 1883 . Por lo tanto, el valor de la información radica en mostrar que la autoridad chilena tuvo que consentir la violencia xenófoba en determinados momentos históricos para transformar la comarca anexada, de una región abierta, internacionalista, cosmopolita y pluriétnica a una provincia-frontera que expresó culturalmente la identidad nacional y los intereses de una elite politica ubicada en Santiago de Chile ${ }^{4}$.

\footnotetext{
${ }^{1}$ La identidad tarapaqueña durante la colonia estuvo ligada a la economía de hacienda, cuando el poder político y económico, así como los principales asentamientos humanos, estaban en los valles de: San Lorenzo de Tarapacá, Camiña, Sibaya, Chiapa, Matilla, Pica y Huatacondo. Posteriormente, la identidad tarapaqueña en la vida republicana se asoció a lo peruano; por ejemplo, el prócer Sr. Ramón Castilla Marquezado nació en el pueblo de San Lorenzo de Tarapacá, entonces capital de la provincia. Y en Pica nació el expresidente del Perú Sr. Remigio Morales Bermúdez. Con el auge del salitre a partir de 1880, aunque el concepto pampino para identificar a los obreros del caliche surge con fuerza, aquello no impidió que la identidad tarapaqueña siguiese representando un referente cultural y político a nivel regional [GONZÁLEZ MIRANDA, Sergio: "Tarapacá. El dios cautivo. Reflexiones en torno al regionalismo de los tarapaqueños del Callao", en Revista Debates en Sociología, n. ${ }^{\circ} 22$, (1997b), pp. 143-145].

2 Ibid., p. 149.

3 TRONCOSO DE LA FUENTE, R.: «Nación, región e integración. El caso de los tarapaqueños peruanos" en Seminario de Historia trinacional Bolivia-Chile-Perú, Arica, 2008, pp. 3-4.

${ }^{4}$ GONZÁLEZ MIRANDA, Sergio: "El Estado chileno en Tarapacá: El claroscuro de la modernización, la chilenización y la identidad regional", en Revista Dialogo Andino, Arica, n. ${ }^{\circ} 13$, (1994), p. 84.
} 
Para concluir, la información analizada proviene del trabajo de archivos realizado en el marco de la investigación doctoral financiada por CONICYT5, 2010-2014. También van mis agradecimientos al Programa de Doctorado en Antropología impartido en conjunto por la Universidad Católica del Norte, de Antofagasta, y la Universidad de Tarapacá, Arica.

\title{
2. Antecedentes teóricos
}

Si bien es cierto que con posterioridad a la guerra del Salitre (1879-1883) el ambiente de efervescencia nacional y xenofobia radicó principalmente en las ciudades de Tacna y Arica, tal atmósfera política no estuvo ausente de la región de Tarapacá, afirmación sostenida en la siguiente lectura del Tratado de Paz y Amistad, firmado por Chile y Perú, en el año 1883:

\begin{abstract}
Desde la perspectiva chilena, el artículo $3 .^{\circ}$ del Tratado de Ancón que le entregaba a Chile por un plazo de diez años las provincias de Tacna y Arica, tenía sentido como una medida táctica para consolidar la soberanía y seguridad de Tarapacá [...]. Por lo anterior, se conjetura que el artículo $2 .^{\circ}$ del Tratado de Ancón fue la finalidad principal de la decisión politica del Estado chileno, es decir, la anexión definitiva e incondicional de la provincia salitrera de Tarapacá. Siendo esta provincia, por tanto, la razón que justificó el conflicto en la frontera norte, especialmente por su importancia económica estratégica ${ }^{6}$.
\end{abstract}

De la cita presentada se desprende que la riqueza minera de Tarapacá llevó a que dicha jurisdicción fuera parte del clima de exacerbación nacional, que desde la perspectiva gubernamental chilena se expresó en una posición que contuvo dos procesos, uno chilenizador y otro desperuanizador, que si bien estuvieron imbricados en lo social persiguieron objetivos distintos y fueron subrayados con intensidades diferentes en la zona de las cautivas Tacna y Arica, y en suelo tarapaqueño ${ }^{7}$. En cuanto a la actitud chilenizadora, consistió en un proceso de transculturación de la zona incorporada a Chile, basado en un Estado de derecho que difundió, legal y arbitrariamente, un cambio cultural dirigido a socializar a los tarapaqueños en los principios de la identidad nacional chilena, en reemplazo de una identidad peruana ${ }^{8}$. Labor socializadora propagada, principalmente, por la educación y complementada por los

\footnotetext{
${ }^{5}$ Actualmente la Comisión de Ciencia y Tecnología (CONICYT) lleva el nombre de Agencia de Nacional de Investigación y Desarrollo (ANID).

6 GONZÁLEZ MIRANDA, S.: PAX CASTRENSE EN LA FRONTERA NORTE 1884- 1929. El 'Factor Tarapacá' en el conflicto entre Perú y Chile por Tacna y Arica. Tesis doctoral en Estudios Americanos, Mención en Relaciones Internacionales, Instituto de Estudios Avanzados (IDEA), Universidad Santiago de Chile, 2003, p. 13.

7 Ibid., pp. 5-13.

8 GONZÁLEZ MIRANDA, Sergio: El Dios cautivo. Las Ligas Patrióticas en la chilenización compulsiva de Tarapacá. 1910-1922, Santiago, Ediciones LoM, 2004a, pp. 27-30.
} 
aparatos ideológicos como la Iglesia y los medios de comunicación, entre otras entidades encargadas de fomentar la cultura, identidad y soberanía chilena ${ }^{9}$.

La principal consecuencia generada por la iniciativa chilenizadora es que para consolidar el rasgo chileno en suelo tarapaqueño difundió clandestinamente una violencia simbólica ${ }^{10}$, y de forma indirecta una violencia estructural $^{11}$, a través de las que el peruano e indígena comenzaron a ser excluidos de lo social y a tener menores oportunidades para acceder a los servicios y derechos entregados por el Estado chileno. Todo ello evidenció que los tipos de violencia mencionados erosionaron el supuesto principio de igualdad que el Estado posterior a 1883 otorgó a los tarapaqueños en su incorporación a Chile ${ }^{12}$.

Mientras, el proceso desperuanizador representó un acto de violencia física e imposición, que también incluyó el desarraigo, la persecución y la expulsión de las personas peruanas, con origen peruano o con afinidades por la causa peruana, proceso desplegado en Tarapacá, particularmente en los años 1911, 1918 y 1919. Si bien en la conformación de las Ligas Patrióticas, instrumento eje de un despliegue desperuanizador, participaron agentes estatales en relación con actores civiles, no es posible afirmar que fueron los gobiernos de Chile (Pedro Montt o Ramón Barros Luco) los que crearon y articularon, intencionalmente, esas organizaciones ${ }^{13}$.

Se puede señalar que el principal impacto de la desperuanización radicó en que sus acciones de violencia física, expulsiones y amedrentamiento psicológico, lentamente, modificaron la trama internacionalista y pluriétnica de la región por una de carácter nacionalista y xenófoba que obedeció a los intereses chilenos $^{14}$. Esto obedeció a una política que la derecha chilena de la época avaló para aplacar no sólo el movimiento sindical internacionalista gestado en

\footnotetext{
${ }^{9}$ GONZÁLEZ MIRANDA, Sergio: «El poder del símbolo en la chilenización de Tarapacá: violencia y nacionalismo entre 1907 y 1950", en Revista de Investigaciones Científicas y Tecnológicas. Serie Ciencias Sociales, n. ${ }^{\circ}$ 5, (1995), pp. 29-39.

10 En palabras de Bourdieu y Passeron (1998), la violencia simbólica facilitó a la autoridad nacional crear una serie de estigmas y prejuicios que, apoyados en los rasgos étnicos y en las manifestaciones socioculturales de la población peruana e indígena, permitieron atribuir de manera arbitraria las cualidades de lo moderno y de lo civilizado al tinte chileno, encerrando una referencia directa a lo peruano e indigena en términos de un ser antimoderno e incivilizado, por lo que debian ser negados y excluidos del nuevo orden nacional [GONZÁLEZ MIRANDA, Sergio: "VIOLENCIA EN LOS ANDES DE TARAPACÁ: Una reflexión teórica», en $R e-$ vista Diálogo Andino, n. ${ }^{\circ}$ 20/21, (2001), p. 25].

11 En palabras de Galtung (1990), la violencia de tipo estructural hizo referencia a una forma indirecta de violencia, que estuvo establecida en las estructuras sociales, manifestada como un poder desigual y, consiguientemente, como oportunidades de vida distinta. Violencia estructural invisible a los ojos, que el mando chileno materializó en una restricción del acceso a los bienes y servicios existentes en la sociedad, así como en el desconocimiento de sus derechos de propiedad de bienes inmuebles y en la posición de excluido y de marginado del tarapaqueño peruano en el nuevo orden social erigido por Chile (GONZÁLEZ MIRANDA, Sergio: "VIOLENCIA EN LOS ANDES...", art. cit., p. 14).

12 GONZÁLEZ MIRANDA, Sergio: PAX CASTRENSE..., op.cit.

13 GONZÁLEZ MIRANDA, Sergio: El Dios cautivo. Las Ligas Patrióticas..., op.cit., pp. 122-135.

14 GONZÁLEZ MIRANDA, Sergio: "Tarapacá: Región en conflicto. 1911-1917", en Revista de Investigaciones Científicas y Tecnológicas. Serie Ciencias Sociales. n. ${ }^{\circ}$ 7, (1997a), p. 47.
} 
la pampa, sino también para apagar la resistencia sindical y estudiantil visibele en otros sectores del país entre 1910 y $1925^{15}$.

En cambio, desde la óptica gubernamental peruana esa atmósfera nacionalista se manifestó en una resistencia peruana que desde Tacna a Tarapacá activaron los pobladores locales para rechazar la ocupación extranjera. Para entender esta rebeldia, especialmente en Tarapacá, debe indicarse que Chile, al incumplir la cláusula $3 .^{a}$ del Tratado de Ancón en la que se fijó que después de diez años de su firma se realizaria un plebiscito para resolver la situación de las cautivas, suscitó en las jefaturas limeñas la deslegitimación del tratado suscrito, incluyendo con esta decisión a la región de Tarapacá. Despertó con ello en la población local la esperanza de que la provincia tarapaqueña volvería, junto a Tacna y Arica, a su cuna de origen (Perú), a pesar que Tarapacá estaba cedida legalmente a Chile desde 1883.

Ahora, para entender el giro de la política chilenizadora, que pasó de aceptar la convivencia cosmopolita y pluriétnica en suelo tarapaqueño a exigir mediante coacción la construcción homogénea de lo social con el matiz chileno, es importante subrayar que hasta 1910 la población tarapaqueña, particularmente aquella con un poder económico y político, continuaba expresando viejas lealtades y solidaridades con la nación de Perú, que impedian consolidar e imponer el ideario de la chilenidad en aquella zona ${ }^{16}$. Debido a este hecho, la autoridad - con objeto de lograr las condiciones para imaginar e imponer la nación de los conquistadores, en un contexto de celebración del centenario de Chile- profundizó un discurso de exacerbación nacional con el fin de crear un escenario en el que promover un proceso de limpieza étnica sustentado por el poder de los vencedores tras una politica deliberada de violencia institucionalizada ${ }^{17}$. De esta forma se abrió un período de violencia xenófoba y racista entre 1911 y 1922, dirigida a martirizar y expulsar a los peruanos por irredentos y cholos obstaculizadores del proyecto político de los dominadores ${ }^{18}$. Aunque las situaciones de violencia extrema sucedieron en los años 1911, 1918, 1919 y 1922, este ambiente ultranacionalista contra lo peruano fue mantenido de forma latente en Tarapacá a través de la labor de los aparatos ideológicos estatales y no estatales como fueron: la escuela, la Iglesia, la masoneria, los clubes sociales, las reparticiones públicas, las fuerzas armadas, los partidos y movimientos sociales y políticos ${ }^{19}$. Lo interesante del fenómeno es que en la reproducción y fomento de un ambiente de chilenización compulsiva participó tanto la sociedad civil como el Estado, tarea ideológica en la que los simbolos nacionales tuvieron un alto contenido de violencia y autoritarismo ${ }^{20}$.

15 GONZÁLEZ MIRANDA, Sergio, Carlos MALDONADO PRIETO, y Sandra MCGEE DEUTSCH: "Las Ligas Patrióticas", en Revista de Investigaciones Científicas y Tecnológicas. Serie Ciencias Sociales. n. ${ }^{\circ}$ 7, (1993), pp. 54-72.

16 GONZÁlEZ MIRANDA, Sergio: Tarapacá: el dios cautivo..., op. cit., p. 148.

17 NÚNEEZ ATENCIO, Lautaro: "Comentario El Dios Cautivo. Las Ligas Patrióticas en la chilenización compulsiva de Tarapacá (1910-1922)", en Revista Chungara. vol. 37, n. ${ }^{\circ}$ 1, (2005), p. 99.

18 Ibid.

19 GONZÁLEZ MIRANDA, Sergio: El poder del símbolo..., op.cit., pp. 29-39.

${ }^{20}$ Ibid. 
La escasa adhesión e identificación de los conquistados con la comunidad imaginada chilena argumentó que en la ingeniería política del Estado y de los grupos de poder la violencia fuese la herramienta central para construir la nación en suelo tarapaqueño entre 1918 y 1922. La razón, entre otras, que explicó que una parte importante de la sociedad civil local (trabajadores, comerciantes, empleados, profesionales, entre otros) participara en las organizaciones promotoras de las acciones xenófobas y racistas contra peruanos, residió en que desde 1910 la cuestión social fue mezclándose con la cuestión nacional, vinculada en Tarapacá con el factor peruano. Este discurso encontró eco, especialmente, en los sectores populares que, producto de su proceso de politización ${ }^{21}$, se encontraban en plena reconfiguración de su impronta identitaria; así, las lealtades de clase fueron mezclándose cada vez más con un sentimiento de apego a la nación de Chile, que llevará a reemplazar su solidaridad internacionalista con el obrero extranjero por una lealtad y adhesión con el Estado-nación, y por ende los llevó a situarse en contra de los trabajadores peruanos y bolivianos, entre otros 22 .

Entonces, siguiendo la argumentación puntualizada, la participación de un segmento importante de la sociedad civil local en las acciones de xenofobia patriotera contra tarapaqueños peruanos se explica por la imbricación gradual de la cuestión social con la cuestión peruana. En ese sentido, dicha población fue representada como una población peligrosa que gozaba de los privilegios de un Estado al que no pertenecian y por ello debian ser excluidos de lo social ${ }^{23}$. Esa participación civil o popular fue canalizada a través de las Ligas Patrióticas, organizaciones cívicas, de carácter nacionalista y tradicionalista, que desde 1918 en adelante - aparte de tener la misión de intimidar y excluir a los peruanos- además fueron instrumentalizadas por los intereses de la derecha liberal con el propósito de ganar adeptos en la pampa salitrera y con ello evitar el avance de anarquistas, socialistas y comunistas en el mundo obrero. Los principales postulados que guiaron el actuar de las Ligas Patrióticas fueron:

El cierre de las escuelas y periódicos peruanos; la prohibición para que peruanos fueran maestros, empleados públicos, empleados de aduanas, de la marina mercante, de los puertos, etc.; que el 80 por

\footnotetext{
${ }^{21} \mathrm{El}$ proceso de politización dentro del marco de la cuestión social es entendido de la siguiente forma: 1) Una formulación discursiva, difundida desde distintos sectores sociales, sobre el lugar que le correspondia ocupar al pueblo trabajador dentro del conjunto del cuerpo social; 2) la articulación orgánica de las demandas populares a través de referentes creados o adaptados expresamente para tal propósito, incluyendo asociaciones de diverso tipo, partidos políticos y comicios electorales; 3) la elaboración de propuestas programáticas destinadas a levantar un diagnóstico y diseñar soluciones para los principales males sociales; y 4) la reivindicación de un principio de ciudadanía popular, entendiendo por tal el derecho de los sectores obreros a participar en la discusión e implementación de aquellas decisiones que afectan a toda la sociedad, y por tanto a ellos mismos [PINTO VALLEJOS, Julio, y Verónica VALDIVIA ORTIZ: ¿Revolución proletaria o querida chusma?: socialismo y Alessandrismo en la pugna por la politización pampina (1911-1932), Santiago, Ediciones LoM, 2001, p. 10].

22 PINTO VALLEJOS, Julio, Verónica VALDIVIA ORTÍZ y Pablo ARTAZA BARRIOS: «Patria y Clase en los Albores de la Identidad pampina. 1860-1890", en Revista Historia, vol. 36, (2003), p. 273.

${ }^{23}$ GONZÁLEZ MIRANDA, Sergio: Tarapacá. El Dios cautivo..., op.cit., p. 148.
} 
ciento de los trabajadores y empresarios fueran de nacionalidad chilena; prohibición de la inmigración peruana; el retiro del consulado peruano en Iquique por ser "innecesario"; la prohibición para que flamearan banderas peruanas en su dia patrio; y la fortificación de las defensas chilenas en el norte ${ }^{24}$.

Entre las acciones de las Ligas Patrióticas estuvieron los mitines patrióticos para celebrar fechas supuestamente gloriosas de la historia chilena; actos de vandalismo y saqueo y acciones de hostigamiento que llegaron incluso a la expulsión forzosa de ciudadanos peruanos. Si bien los actos desperuanizadores fueron ejecutados por civiles (profesionales, comerciantes, empleados públicos y trabajadores), no se puede negar que en ocasiones existió el compromiso o consentimiento de algunas autoridades estatales con ese tipo de expresiones $^{25}$. Ejemplo de ello es la entrevista realizada al senador de la provincia Sr. Arturo del Río en el diario El Mercurio, que ayuda a explicar la visión favorable existente entre las autoridades chilenas sobre la Liga Patriótica. Respecto a la actitud que dicha organización civil poseyó en los hechos de $1911^{26}$, el senado indicó:

Debo empezar por manifestarles que las informaciones que han llegado a Santiago, respecto a las manifestaciones patrióticas que ha organizado esa institución, han sido abultadas [...]. El espiritu que se tuvo al organizar esa liga fue evidentemente laudable y sincero. El predominio que iba adquiriendo el elemento peruano era bastante poderoso y se hacia indispensable que una institución atajara ese avance que se extendia a todo Tarapacá. Y para probar que esto que yo les voy diciendo es la verdad absoluta, basta mencionar las instituciones que los peruanos habian instituido en la provincia, y ahi tiene Ud. el casino, el club, la Bomba, escuelas, diarios y una poderosa logia secreta. Concluir con este avance inusitado fue y ha sido el espiritu de la Liga Patriótica. Yo no he estimado jamás - nos agregó el señor del Río- que la Liga haya sido una amenaza contra la Constitución y las leyes del país, ni mucho menos contra las más elementales garantias de los extranjeros ${ }^{27}$.

La violencia de las Ligas Patrióticas contra el peruano, los descendientes de peruanos y aquellos que defendieron la cuestión peruana, llevó a que una población considerable de Tarapacá fuese expulsada con destino a Perú ${ }^{28}$ entre 1918 y 1922. Esta realidad mostró que en esa época las relaciones entre

${ }^{24}$ GONZÁLEZ MIRANDA, Sergio, Carlos MALDONADO PRIETO, y Sandra, MCGEE DEUTSCH: Las Ligas Patrióticas..., op. cit., p. 59.

25 GONZÁLEZ MIRANDA, Sergio: El Dios cautivo. Las Ligas Patrióticas..., op.cit., p. 135.

${ }^{26}$ Los sucesos de 1911 en la ciudad de Iquique fueron producto del rumor esparcido por la prensa chilena sobre el asalto al consulado de Chile en el Callao, Perú, cuyo propósito fue agitar los ánimos de la población local que desembocaron en actos de violencia vividos en el consulado, casino y edificio de la Bomba de la colonia peruana en Iquique. Pese a la gravedad de los hechos, la Liga Patriótica continúo con sus actividades en Tarapacá (Ibid., pp. 59-60). 27 Biblioteca Nacional de Santiago (en adelante BNS), Diario El Mercurio de Santiago, p. 16, 29 de noviembre de 1911.

28 El estudio de Troncoso, a pesar de indicar que no cuenta con cifras exactas sobre el número de tarapaqueños repatriados, cita varias fuentes para mostrar en cifras la realidad de la expulsión: El número de repatriados llegados a la capital oscila entre 18.000 (La voz del sur, Lima 
chilenos y peruanos fueron enmarcadas por la autoridad chilena en la distinción amigo/enemigo, que imbuidas de una lógica racista justificaron la promoción de una visión etnocentrista sobre la otredad que - sostenida en estigmas y prejuicios - hizo posible desplegar una serie de acciones dirigidas a despreciar y violentar la diferencia cultural y nacional representada por los tarapaqueños peruanos ${ }^{29}$. Es factible conjeturar que a través de la ecuación amigo-enemigo la autoridad chilena pudo recurrir a la violencia para generar una ruptura histórica con la anterior forma nacional y cultural de organizar Tarapacá, consiguiendo así la consolidación del cambio cultural que todavía tenía pendiente la imposición de la comunidad imaginada de los conquistados en suelo tarapaqueño.

En fin, para concluir, constatamos que el consentimiento del procedimiento de las Ligas Patrióticas respecto a las autoridades estatales no solo obedeció a que encarnaron una herramienta de violencia que logró anular y excluir a un grupo social contrario al nuevo orden nacional, sino que también aquellas expresaron una liturgia politica, pues estas acciones - por más irracionales que fueran - tuvieron un trasfondo simbólico referido a glorificar de forma extrema lo nacional, su identidad y cultura ${ }^{30}$. De este modo se transformó la Liga Patriótica en un mecanismo que reforzó la razón de Estado de Chile dirigida a fortalecer la soberanía en el territorio ganado por las armas, y por tal motivo el poder político las consideró funcionales en relación con sus intereses entre 1918 y 1922. Posteriormente a esa época, las Ligas Patrióticas dejaron de servir a los ojos de la autoridad porque su violencia patriotera y xenófoba colocó en riesgo la legitimidad del derecho de anexión de Tarapacá a los ojos de la comunidad internacional, y también desfavorecía su posición en el conflicto por las cautivas de Tacna y Arica ${ }^{31}$.

\section{Antecedentes metodológicos}

Los datos analizados fueron obtenidos del Archivo Intendencia de Tarapacá, Archivo Histórico de Santiago, Biblioteca Nacional de Santiago y Biblioteca Santiago Severin de Valparaíso. Se trata de fuentes que ayudaron a recrear el escenario histórico referido a la segunda fase de expresiones violentas ejercitadas por las Ligas Patrióticas en la antigua Tarapacá. Además, permiten apreciar las opiniones o visiones de agentes locales y nacionales sobre los actos de violencia ocurridos en dicha ciudad. Por lo tanto, los documentos representan una fuente clave, tanto para describir el ambiente sociopolitico de la época como para captar los discursos y opiniones desarrollados por actores politicos locales y nacionales sobre la actuación de las Ligas Patrióticas en

31 de marzo de 1921, p. 1), 30.000 (Vargas 1921: XII), 40.000 (El tarapaqueño, Callao 31 de octubre de 1975, p. 3) y 50.000 (Málaga, 1919:93) (TRONCOSO DE LA FUENTE, R.: "Nación, región e integración...", art. cit., p. 5).

29 TODOROV, Tzvetan: La conquista de América. El problema del otro, Madrid, Siglo XXI, 1987, p. 13.

${ }^{30}$ BLAIR TRUJILLO, Elsa: "Violencia e identidad”, en Revista Estudios Políticos, n. ${ }^{\circ} 13$, (1998), pp. 137-153.

${ }^{31}$ GONZÁLEZ MIRANDA, Sergio: El Dios cautivo. Las Ligas Patrióticas..., op. cit., p, 38. 
suelo tarapaqueño ${ }^{32}$. Por último, tomando en cuenta que los diarios consultados (El Mercurio de Santiago y El Mercurio de Valparaiso) fueron proclives a exaltar la posición oficial chilena existente en la época, fue necesario efectuar un proceso de triangulación de la información periodística con otras fuentes históricas e investigaciones del tema para así evitar el sesgo de caer en una reconstrucción de los hechos desde la lógica del poder o desde la mirada de los conquistadores, y con ello tener una fotografia lo más fiel a los sucesos investidos ${ }^{33}$.

\section{Antecedentes históricos del área de estudio}

En una mirada de largo aliento, la antigua región peruana de Tarapacá conquistada por Chile, tras la guerra del Salitre (1879-1883) fue parte del corregimiento de Arica, establecido el 17 de agosto de 1565 por el poder hispano, cuyos límites fueron: por el oeste delimitó con el océano Pacífico; por el sur, con el corregimiento de Atacama; por el este, con los corregimientos altiplánicos de Lipez, Paria, Carangas, Pacajes y Chucuito; y por el norte, con los corregimientos de Ubinas y Arequipa ${ }^{34}$. Con posterioridad, Tarapacá fue separado de la jurisdicción de Arica, convirtiéndose en el año 1768 en un nuevo corregimiento, proceso promovido para mejorar el control español sobre la minería de la plata, que en el s. XVIII tuvo su mayor apogeo ${ }^{35}$. El desarrollo de la minería en Huantajaya y Santa Rosa llevó a la autoridad hispana a establecer sus centros socioadministrativos y religiosos en los valles, quebradas y oasis de la zona de piedemonte, ubicados entre los 1.000 y $2.500 \mathrm{~m} \mathrm{~s}$. n. m., y en aquellos pueblos principales de los valles serranos prealtiplánicos, situados entre los 2.500 y $3.500 \mathrm{~m} \mathrm{~s}$. n. m., para crear un mercado interno que proveyera los insumos que necesitó la explotación de plata y otros minerales. Esta dinámica económica condujo a la aparición de una burguesía hacendado-minera y de una aristocracia local, principalmente en la zona de piedemonte de Camiña bajo, San Lorenzo de Tarapacá y Pica-Matilla, circunstancia que en el devenir histórico supondrá una injerencia relevante en los asuntos públicos de la región ${ }^{36}$.

Con el nacimiento del Estado peruano, en el año 1821, Tarapacá obtuvo el estatus de provincia, quedando incorporada en el departamento de Arequipa, creado en 1822. Luego, con las medidas de redefinición administrativa formó parte Tarapacá (1837) del departamento litoral de Moquegua, y desde el 1 de

\footnotetext{
32 SOTO LARA, José: "La prensa española como fuente histórica para el problema de Tacna y Arica (1880- 1901): Heurística y método", en Revista de investigación multidisciplinar, n. ${ }^{\circ} 7$ (2014), pp. 52-42.

33 ALZÁS GARCÍA, Teresa, Luis CASA GARCÍA, Ricardo LUENGO GONZÁLEZ, José TORRES CARVALHO, y Sofia VERÍSSIMO CATARREIRA: "Revisión metodológica de la triangulación como estrategia de investigación", en Revista Investigación Cualitativa en Ciencias Sociales, vol. 3 (2016), pp. 639-648.

34 GUNDERMANN KRÖLL, H.: "Comunidad, sociedad andina y procesos socio-históricos en el norte de Chile", tesis doctoral, Centro de Estudios Sociológicos, Colegio de México, 2001. 35 Ibid.

36 NÚÑEZ ATENCIO, Lautaro: "La Tirana del Tamarugal. Del ministerio al sacramento", Antofagasta, Universidad Católica del Norte, 2004.
} 
diciembre de 1868 pasó a formar la provincia litoral de Tarapacá37. En una época peruana (1821-1880) Tarapacá estuvo marcado por la actividad salitrera que adquirió notoriedad, especialmente, con la labor de Tadeo Haenke que llegó a Perú en 1790 para trabajar en un procedimiento para separar y beneficiar el caliche 38 (de 1810 a 1812, en la pampa salitrera de Negreiros, Pampa Negra y Zapiga, se levantaron entre siete $u$ ocho oficinas para elaborar salitre $\left.{ }^{39}\right)$. Un hito que marcará el auge de la industria minera fue la medida tomada el año 1840 por Ramón Castilla, ministro de Hacienda, que decretó libre de derechos la extracción del salitre de Tarapacá, medida que motivará a los industriales a invertir capitales para mejorar los procesos productivos del oro blanco ${ }^{40}$.

El antiguo Tarapacá peruano, antes de la guerra del Salitre (1880-1883), según un informe de $1881^{41}$ que no posee fecha, referia que la región en 1875 poseía los siguientes lindes: por el norte, con la provincia de Arica; por el sur, río Loa; por el este, Bolivia; y por el oeste, el océano Pacífico. Internamente estuvo organizada de la siguiente manera: en la faja costera o litoral radicaron los puertos de exportación del salitre, como fueron Iquique, Pisagua y Caleta Buena, además de sectores menores como Patillos, Junín, Mejillones, Pabellón de Pica, Huanillos y Punta de Lobos. En la pampa tarapaqueña residieron las oficinas salitreras, destacando La Noria, Pozo Almonte, Paposo, Alianza, entre otras. En los espacios de costa y pampa la población característica, aparte de la peruana, fue el componente extranjero que, por asuntos de migración, comerciales, diplomáticos y laborales radicaron en la columna vertebral de la empresa salitrera. Posteriormente, estuvieron los valles bajos o piedemonte, marcados por una elite hacendado-minera de raíz española situada en los sectores de Camiña Bajo, Tarapacá Bajo y Pica. Esos grupos de poder también ocuparon zonas de los valles altos, como los pueblos de Sibaya y Mamiña. Por último, estuvieron los sectores de precordillera y altiplano, donde reinó la población vista de india para la época ${ }^{42}$.

Sobre esta provincia tarapaqueña, con una población originaria diferenciada nacional y étnicamente, después de la anexión a Chile recaerá un cambio cultural dirigido a imponer, incluso por la coacción, los contenidos de lo chileno en reemplazo de lo peruano. Ese proceso chilenizador, en los pisos ecológicos

37 GUNDERMANN KRÖLL, H.: Comunidad, Sociedad andina..., op. cit.

38 FLORES SORIA, Carlos: "Billinghurst y las salitreras de Tarapacá (1872-1876)", en Revista Desde el Sur, n. ${ }^{\circ}$ 10, (2008), p. 99.

39 Ibid.

40 GONZÁLEZ MIRANDA, Sergio, y Diego LIZAMA GAVILÁN: "El estanco salitrero en Tarapacá y el liberalismo peruano: las influencias "castillista" y "civilista" (1844-1873)", en Revista Aldea Mundo, n. ${ }^{\circ} 48$ (2019), pp. 45-46.

${ }^{41}$ Archivo Histórico de Santiago (en adelante AHS), Libro Secretaría Municipal, v. 4/ n. ${ }^{\circ} 121$, Fjs.: 121-128, 1881 .

42 GUNDERMANN KRÖLL, Hans: "Comunidad indígena y Ciudadanía. La experiencia aymara en el norte de Chile», en Revista Allpanchis, n. ${ }^{\circ} 46$, (2005), pp. 91-130. GONZÁLEZ CORTEZ, Héctor, y Vivian GAVILÁN, VEGA: "Apuntes sobre el tema de la identidad cultural en la Región de Tarapacá", en Revista Estudios Atacameños, n. ${ }^{\circ}$ 13, pp. 27-45. GAVILÁN VEGA, Vivian, y Ana CARRASCO GUTIÉRREZ: "Festividades Andinas y Religiosidad en el Norte chileno", en Chungará. Revista de Antropologia chilena, vol. 41, n. ${ }^{\circ}$, (2009), pp. 101-112. 
de costa-pampa, valles tarapaqueños y altiplano tendrá contenidos particularidades e intensidades distintas para conseguir imponer y consolidar la soberanía chilena en la jurisdicción conquistada. A continuación se ofrece un mapa sobre la provincia de Tarapacá.

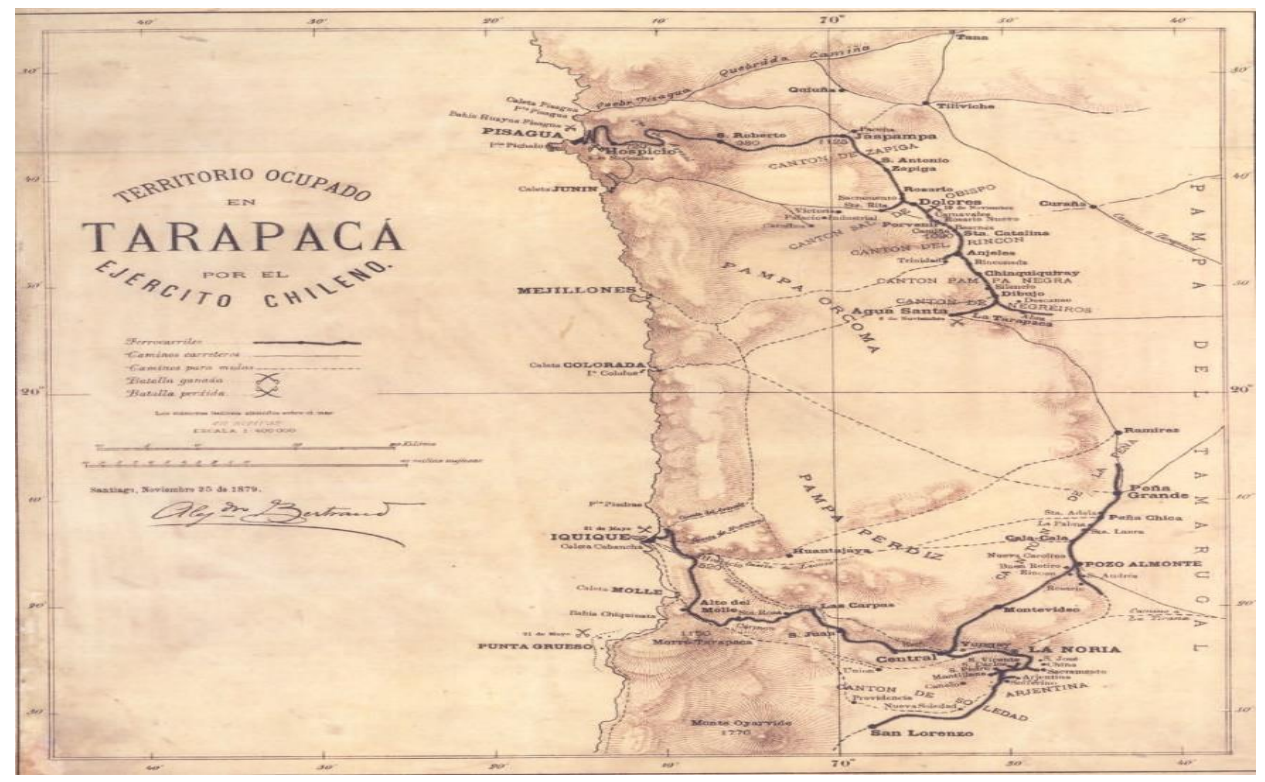

Imagen 1: Mapa de Tarapacá ocupado por el ejército chileno, 1879. Fuente: Memoria Chilena, Biblioteca Nacional de Chile (Documento de uso público)

\section{E1 recrudecimiento de un ambiente xenófobo y racista en suelo tara- paqueño, 1918-1922}

Uno de los factores que colaboró en crear las condiciones para el rebrote de la violencia patriotera y racista contra el peruano y los defensores de la causa peruana fue la iniciativa del derecho a la autodeterminación de los pueblos que el presidente estadounidense Woodrow Wilson, como parte de los 14 puntos formulados un 12 de febrero de 1918 para promover la democracia y libertad en las relaciones internacionales, después de acabada la Primera Guerra Mundial. Este principio será asumido por el presidente peruano José Pardo para rechazar el Tratado de Ancón de 1883 por la dilación chilena en el cumplimiento del plazo para realizar el plebiscito y zanjar la situación territorial de Tacna y Arica, lo que trajo consigo que la diplomacia limeña intensificara su exigencia por el retorno, no solo de las cautivas Tacna y Arica a Perú, sino también de Tarapacá ${ }^{43}$. Esa campaña peruana por recuperar los territorios ocupados por Chile produjo la reactivación de un ambiente de nacionalismo en la provincia de Tarapacá, que será propagado entre otros por los medios de comunicación. Sobre la actitud peruana de ligar la cuestión de Tacna y Arica a la libertad de los pueblos proclamada por Wilson, el diario El Mercurio de Valparaíso publicó la siguiente nota:

43 BASADRE GROHMANN, Jorge: Historia de la República de Perú, Perú, Editorial Universitaria, 1974 . 
Expresamos nuestro anhelo, cimentado en los más intimo del alma chilena, tributaria del derecho y de la justicia, que quiere y exige la pronta declaración de que las provincias de Tacna y Arica formen parte integrante e inviolable del territorio nacional [...].

Para los chilenos del norte no hay en esto cuestión de ninguna clase: Tacna y Arica son chilenas, porque en ellas se ha infiltrado nuestro propio espiritu de raza. Nuestras leyes y costumbres han regido esos territorios por cerca de cuarenta años y los rigen aún 44 .

En este contexto de ultranacionalismo dirigido a fomentar la animadversión contra lo peruano fueron organizados los actos a favor de Chile en los pueblos de Iquique y Pisagua. El mitin de Iquique fue descrito en los siguientes términos por el Diario El Mercurio de Valparaiso:

El mitin verificado esta noche ha resultado de enormes proporciones. El orden y compostura fueron la nota brillante de la manifestación, en la que formaron alrededor de cinco mil ciudadanos.

La columna, que ocupaba más de ocho cuadras, se detuvo frente a la casa del intendente, señor Amengual, para rendirle homenaje a este funcionario, como sobreviviente de Pisagua.

Hablaron el presidente de la Sociedad de Veteranos del 79, el secretario de la Intendencia, y el abogado señor Allende Castro. Todos los discursos fueron recibidos con grandes aclamaciones, en la que se pedia la anexión de Tacna y Arica por el Congreso.

El desfile terminó en la Plaza Condell, donde hablaron el alcalde señor Godoy y el diputado señor Blanlot Holley, quien leyó las conclusiones, en las que se pide que de una vez, despreciando las amenazas del pais que nos provoca a la guerra, se solucione el llamado problema de Tacna y Arica, en la única forma que el pais exige, y poniendo término a las campañas de odios que con inaudita tenacidad sostienen los peruanos que aqui se enriquecen ${ }^{45}$.

No obstante, el mitin de Iquique fue calificado por El Mercurio de Valparaíso en su portada como: Un gran desfile patriótico [...]. Sin odios para nadie. El desfile fue imponente. Se notaba gran profusión de banderas y faroles y se lanzaron voladores y grandes vivas a la patria. El desfile fue acompañado por las bandas de músicos de la guarnición y se pronunciaron hermosos y patrióticos discursos ${ }^{46}$. Incluso el señor Amengual, intendente de Tarapacá, aseguró que en el mitin no habia habido desmanes populares y que garantiza que el orden público se mantuvo inalterable 47 . Para el cónsul peruano aquel acto había sido promovido para vejar a sus connacionales $y$ asaltar sus propiedades ${ }^{48}$. Esto lo

\footnotetext{
44 Archivo Biblioteca Santiago Severin (en adelante BBS), diario El Mercurio de Valparaiso, portada, 3 de noviembre de 1918 .

45 Ibid.

46 Ibid.

47 BNS, diario El Mercurio de Santiago, p. 14, 6 de noviembre de 1918.

48 BSS, diario El Mercurio de Valparaiso, portada, 3 de noviembre de 1918.
} 
corroboró con el reportaje del diario El Despertar de los Trabajadores, que permitió describir, en parte, los desmanes provocados por la manifestación patriótica ocurrida en Iquique:

Una vez terminado el comicio, en el que se leyeron las peticiones de anexión definitiva a Chile de las Provincias de Tacna y Arica, la muchedumbre se repartió en numerosos grupos hasta el amanecer recorrieron las calles profiriendo vociferaciones, vivas y mueras.

Fueron asaltadas las sombrerias situadas en B. Arana $n .^{\circ} 115$, cuyo propietario es Miguel Rivera, quien se habia ausentado durante el dia con su familia; la sastrería vecina a la sombrería $n .{ }^{\circ} 113$, donde se derribaron las puertas y quebraron vidrios de las ventanas; la sastrería "Aysén", de Eusebio Zambrano, situada en la calle Juan Martinez con Tarapacá, donde se dispararon repetidos disparos de revólver, cuyas balas han quedado incrustadas en los tableros de la ventana y en la puerta; una casa situada en la calle de O'Higgins entre B. Arana y Amunátegui, a la cual una lluvia de piedras le rompió completamente los vidrios y obligó a los moradores a huir por el interior hacia el vecindario en demanda de auxilió ${ }^{49}$.

En lo que respecta al acto de la Liga Patriótica en el pueblo de Pisagua, el documento del archivo de la Intendencia de Tarapacá detalló:

$V$. S. debe estar en conocimiento y posesión de los hechos desagradables ocurridos anoche a las $20.30 \mathrm{~h}$ con motivo de un desfile que con la banda municipal a la cabeza, hizo gran parte del pueblo chileno de este puerto y auspiciado por el directorio de la Liga Patriótica [...].

Ya en ocasión anterior, y también bajo los auspicios del directorio de la Liga Patriótica y con el concurso de la banda municipal, habiase organizado otro desfile que, recorriendo las calles de la ciudad, cometió pequeños desmanes $y$ desbordes contra algunas propiedades de residentes peruanos aqui. Esta situación ya pasada, que originó apreciaciones contradictorias sobre los hechos ocurridos, habiase acallado hasta el punto que parecía estar ya olvidada. Desgraciadamente, anoche ha vuelto a reproducirse una situación análoga a la anterior, con la agravante de que la columna desfilante ha penetrado a algunas casas-habitaciones de peruanos en esta, destruyendo y malogrando cuanto pudieron encontrar 50 .

A la vez, un segundo documento detalló los nombres de las personas que sufrieron desmanes producto de la manifestación realizada en el pueblo de Pisagua. Estos fueron:

Carlos Vargas Abadia, calle Prat 47: vidrios de las ventanas despedazados a pedradas. Augusto Otero, calle Arica n. ${ }^{\circ}$ 45: descerrajaron la puerta haciendo pedazos especies y muebles que habia en el interior de las casas. Marcelina $V$. de Skinner, calle Angamos n. ${ }^{\circ}$ : vidrios

49 GONZÁleZ MIRANDA, Sergio: El Dios cautivo. Las Ligas Patrióticas..., op. cit., p, 82. 50 Archivo Intendencia de Tarapacá (en adelante AIT). Libro Huelga de Cargadores y Cancheros 1917, vol. 13, s/n. ${ }^{\circ}$, fjs.: 174-175, 22 de noviembre de 1918. 
de las ventanas despedazados. Manuel Loayza, Estación: penetraron al interior de la habitación y rompieron los muebles, espejos y objetos de casa. Emilio Prado, calle Ramirez esq. Chorrillos: puertas y ventanas despedazadas. Arturo Rojas, calle C. Condell n. ${ }^{\circ}$ 36: vidrios de las ventanas despedazados. Sofía A. de Bruce, plaza Santa Maria: pedradas, y le rompieron la cabeza a Eusebio Maniel, esposo de esta ${ }^{51}$.

La violencia nacionalista desatada en los pueblos de Iquique y de Pisagua encarnó una práctica de reivindicación política dirigida a reclamar la exclusividad de lo nacional en las fronteras de lo chileno, en un momento en que en el territorio conquistado existía una población importante económica y socialmente que impedia constituirse a la nación de Chile en una comunidad socialmente homogénea, capaz de convertirse en una realidad indiscutible para la sociedad civil local. Por esta razón, la autoridad, para lograr el objetivo de que Tarapacá perteneciera simbólicamente a la unidad política territorial de los conquistadores, fomentó un ambiente de exacerbación nacionalista en el que el peruano tarapaqueño fue señalado en su condición de enemigo ${ }^{52}$; no solo para sobrevalorar lo chileno en términos de progreso y civilización frente a lo peruano presentado como símbolo del atraso, sino también para justificar cotidianamente el hostigamiento y violencia xenófoba para anular y excluir al otro del nuevo orden nacional.

Por ese motivo la autoridad chilena consintió a las Ligas Patrióticas: porque ellas representaron verdaderas liturgias políticas ${ }^{53}$ en las que la dinámica de la dialéctica amigo-enemigo, aparte de legitimar la anulación y exclusión del tarapaqueño peruano, también estuvieron orientadas a propagar discursos, himnos, hitos históricos y simbolos patrios que —apoyados en la coacciónpersiguieron delimitar las fronteras de lo nacional, estructurar el comportamiento ciudadano y propagar una cultura nacional según los intereses dictados por la inteligencia politica central. Así se transformaron las Ligas Patrióticas en una herramienta funcional para los grupos de poder en aquella coyuntura histórica. porque su violencia contra el peruano colaboró a revitalizar una conciencia nacional a favor de Chile.

Aunque la violencia terrorista de las Ligas Patrióticas recayó básicamente en el sector costero-pampino de Tarapacá, por estar ahí el circuito administrativo y productivo del salitre, igualmente su agresividad xenófoba fue patente en los valles tarapaqueños mediante publicaciones ocasionales, dirigidas a esparcir el terror sobre la población peruana. Entre esas publicaciones destacó el pasquín Liga Patriótica con su artículo Tarapacá y otros pueblos, publicado en el año 1919, para referirse a los peruanos de los valles. La nota señaló:

Este pueblo y sus alrededores es lo más abandonado a su suerte.

\footnotetext{
51 AIT. Libro Huelga de Cargadores y Cancheros 1917, vol. 13, s/n, fjs.: 180-186, 22 de noviembre de 1918.

52 GONZÁLEZ MIRANDA, Sergio: «Pax castrense en la frontera norte. Una reflexión en torno a la post-guerra del Salitre: el conflicto por Tacna-Arica y Tarapacá", en Revista Universum, n. ${ }^{\circ}$ 19, (2004b), p. 51

53 BLAIR TRUJILLO, Elsa: "Violencia e identidad...", art. cit., pp. 140-141.
} 
Las autoridades no le presan la atención que es necesaria.

Aqui es el refugio de todos los malvados e intrigantes espias peruanos, a los que ya era bueno aplicarles la ley de residencia.

Todos los que salen de las oficinas se dirigen a refugiarse a Tarapacá $y$ pueblos circunsvecinos donde se creen fuertes e inamovibles.

En Tarapacá el tinterillo Torres, el cantinero Núñez y el vago Loayza forman una trinidad explotadora de esta región.

En Pica, los pocos chilenos que hay pasan la vida más aporreados, por cuanto el cholaje ejerce aqui el boycoteo permanente de los chilenos, que tienen que pasar mil penurias.

Es increible cómo domina aquí el elemento cholo. El único remedio sería el arrasar este pueblo desde sus cimientos, para levantarlo de nuevo como población chilena.

De Matilla se puede decir lo mismo que de Pica y Canchones, que son del mismo molde.

En Limasiña, hay los Zamora, Zacalde, Jilaya, Garcia, Cayo, Caqueo, etc., que no hay quien les pare un dedo.

En Mocha están los Vilca y Oxa, que son los taitas, sin cuya voluntad no vuela una mosca.

En Sibaya, los cabezas, Argandoña, Daniel Pérez y Anacleto Mollo son los caciques de horca y cuchilla.

En Caihua, los famosos Buitrones, verdaderos buitres de tragaderas descomunales, los Quiroga y Braulio Borda. ¿Quién se atreve contra ellos?

En Huaviña, los Castro, Juan Zocale, Teodoro García, Pablo Rocha y Felipe Jachara, como los de los otros pueblos.

En Pachica, otros Vilca, el gran Raimundo Guacte, que debia estar en la cárcel o ser expulsado. Es un verdadero maximalista, hay que conocerlo a este jesuita de la Inquisición de Lima.

Los Galeas, Soto, Ramirez y Salazar.

En Laonzana, hay otro grupo pariente de los ya nombrados de esos pueblos vecinos, que ejercen su propaganda diaria en nuestra contra. Los moradores y explotadores de todos los pueblos nombrados son como la piedra fundamental de la propaganda peruana en la provincia. De alli convergen, esparcen, concentran todas las actividades peruanas.

Esos poblados se han dejado siempre en abandono y los peruanos han estado en ellos como reyes y señores, $y$ siendo hasta peruanas las mismas autoridades locales.

No nos cansaremos de insistir sobre una enérgica acción desperuanizadora de esos centros que hacen verdaderas calamidades dentro de la provincia hasta obtener su más perfecta chilenización.

Apelamos al elevado patriotismo de nuestras autoridades para que se penetren de lo que apuntamos, y estudiada esa situación le ponga remedio ${ }^{54}$.

${ }^{54}$ BNS, Pasquín La Liga Patriótica, 5 de enero de 1919, p. 3. 
En ese mismo año55 el pasquín El Eco Patrio publicó una nota sobre peruanos en el pueblo de Pica en los siguientes términos:

En Pica, que es la fábrica de peruanos aqui, en pleno Chile, ha sentado sus reales el sastrecillo que dice apedillarse Paz, pero que por lo que está haciendo no hace honor a su apellido, pues en su casa reúne a [ilegible] de mosalvetes que no tienen 18 años y los instruye en tal forma que está haciendo de [ilegible] ociosos a unos buenos insultadores de Chile.

[...] El 25 de diciembre unos cuantos de estos enseñados por el sastre Paz y que son chilenos por haber nacido aqui, pero que por la jeta perecen peruanos, andaban por la calle vivando al Perú ${ }^{56}$.

Los pasquines La Liga Patriótica y El Eco Patrio fueron parte de la prensa nacionalista xenófoba, que difundieron el terror y hostigamiento contra peruanos y adherentes de la causa peruana a través de la divulgación detallada de personas con sus nombres y lugares en los que habitaban; prensa en la que, para justificar su discurso de intimidación contra el otro en los pasquines, la población peruana fue presentada como malvados e intrigantes espias, vago, chojaje, elemento cholo, caciques de horca y cuchilla, se creen fuertes $e$ inamovibles, entre otros calificativos que sirvieron para construir un imaginario social que avalase la animadversión, el odio y las prácticas de exclusión contra los peruanos. También hay que indicar que, producto del ambiente de intimidación divulgado por medio de la prensa nacionalista chilena, hubo peruanos que abandonaron voluntariamente Tarapacá para no vivir experiencias de violencia ya experimentadas en la región.

El discurso chileno para promover la exclusión de los peruanos de la jurisdicción conquistada no solo pasó por representar al otro como un elemento que obstaculizó la construcción del proyecto político del Estado-nación de Chile; además, el elemento peruano fue visto en el marco de la cuestión social en el sentido de ser el problema que ocasionó la falta de oportunidades de trabajo para los chilenos. Sobre esto El Mercurio en 1920 publicó una nota del diputado Sr. Carlos Alberto Ruiz, presidente de la comisión para estudiar los problemas del norte. En lo referente a Tarapacá indicó:

En esta provincia existe el problema peruano, pues muchos empleados superiores de las oficinas salitreras, conjuntamente con un gran número de trabajadores de la misma nacionalidad, se preocupan de hostilizar sistemáticamente a los chilenos. En resumen [...] puede decirse que en el norte la cuestión social es grave y honda y que urge ponerle

\footnotetext{
55 Si bien el pasquín El Eco Patrio no posee fecha de publicación, fue ubicado en el año 1919, porque en ese año proliferaron una serie de pasquines patrioteros que promovieron la violencia contra los peruanos tarapaqueños y simpatizantes de la causa peruana (GONZÁLEZ MIRANDA, Sergio, Carlos, MALDONADO PRIETO y Sandra MCGEE DEUTSCH: Las Ligas Patrióticas..., op.cit., pp. 64-65).

56 BNS, Pasquín El Eco Patrio, s/f., p. 8. Documento cedido por el Sr. Enelidolfo Orreal, oriundo del pueblo de Pica.
} 
remedio si no se quiere verla llegar pronto a extremos que serian dolo$\operatorname{rosos}^{57}$.

Desde la autoridad nacional, la imbricación de la cuestión social con la cuestión peruana en el sentido de que los peruanos fueron los causantes de la pauperización y explotación -incluso del hostigamiento que cotidianamente vivian los chilenos- ayudó a profundizar una pertenencia y lealtad de un segmento de los trabajadores con Chile, en la medida de que el obrero, con la finalidad de mejorar sus condiciones de vida, asumió un discurso de solicitar al Estado y a la clase patronal la solución a sus problemas. Esto supuso su solidaridad con el Estado-nación chileno y su oposición con el mundo trabajador peruano, y extranjero en general ${ }^{58}$.

Producto de la violencia compulsiva de carácter física y psicológica, entre 1918 y 1920 comenzó la salida de familias de Tarapacá, así como de trabajadores que habian llegado a la pampa salitrera en busca de una mejor vida. Si bien no hay cifras exactas acerca de las expulsiones, El Comercio, diario peruano, informó de que en los meses de enero y febrero del año 1919 llegaron 13 vapores procedentes de Iquique con 4.449 repatriados ${ }^{59}$. También este clima de violencia xenófoba ocasionó que muchas personas de los valles tarapaqueños optaran por el exilio voluntario a zonas de Perú y Argentina60. Un caso de ostracismo voluntario fue el de la Sra. Elvira Brañes, que en la tercera década del s. Xx marchó a la ciudad de Callao. Mostramos una carta enviada por ella a su sobrino para vender las propiedades dejadas en Chile (27 de octubre de 1939:

\section{Señor Luis A. Brañes}

Apreciado sobrino:

Recibi tu carta atrasada en la que me he impuesto de todo deseo que siga tu mejoria en unión de la familia, a quienes saludas. Respecto á Biljajua, tú eres el único dueño; mi parte la vendi, y la de mi hermano Edilberto que me correspondia [...]. Como tu papá mandó los 250 pesos, sus hermanos no tienen derecho, según carta que le escribi a él. Para que estés más seguro, mándame dinero para mandarte en certificado la escritura Biljagua, y los 300 soles que mandaron en todos eran arriendos atrasados que debia tu papa.

Para estar seguro de lo que tú dices que mi papá te arrendó, mándame el papel para verlo; según eso haré arreglo contigo. Quiero ver la fecha, yo procuro la tranquilidad entre hermanos [...].

En otra carta escribi la parte de Moquella, que es de mi hermano finado Edilberto, quien la poseí, y Chillaiza, quien lo tiene arrendado.Deben decir tú y tus hermanos si la vendo.

\footnotetext{
57 Biblioteca Nacional de Santiago, diario El Mercurio de Santiago, p. 14, 17 de mayo de 1919. 58 PINTO VALLEJOS, Julio, y Verónica VALDIVIA ORTIZ: Revolución proletaria..., op.cit., pp. $10-15$.

59 TRONCOSO DE LA FUENTE, R.: "Nación, región e integración...", art. cit.

60 Dato proporcionado por la Sra. Elba Morales. 94 Años. Originaria del pueblo de Valle de Quisma.
} 
Si no son unidos en reunir la plata y mandarme, estoy muy necesitada; yo pienso en arrendar en 350 pesos... No se descuiden en mandar y escribir; como estoy muy pobre, tendré que mandar una persona apoderada se imponga de las entradas [...].

Si son buenos sobrinos conmigo, y en particular tú, te haré una venta. Hay vemos pedasos en Quisama la Colcha o Coica, en Quitagama hay un pedaso de sembrio que arriendo [...].

Diles a tus hermanos [...] si les gusta algún pedazo para arrendarles, y muchos saludos a cada uno en particular.

$Y$ tú, recibe un fuerte abrazo de tu tía. Elvira Brañes ${ }^{61}$.

Una de las consecuencias de la violencia chilenizadora fue que con sus acciones provocó el quiebre de familias, ya que una parte dejó la región de Tarapacá para no sufrir prácticas de hostilidad, mientras que para otros el apego a su terruño donde estaban sus propiedades, fuente laboral y su historia familiar, los llevó a mantenerse en suelo tarapaqueño, pese al clima de discordia existente. El caso de la Sra. Elvira Brañes exterioriza no solo la separación de familiares, sino que además enseña cómo ella pasó de manejar tierras que implicaban una calidad de vida a subsistir muy pobre, necesitada, en el puerto de Callao de Perú, obligándose a vender sus propiedades agrícolas para sostenerse. Por lo tanto, los exiliados tarapaqueños, ya sea de forma forzada o voluntaria, experimentaron una doble violencia: por un lado, la desatada por el clima chilenizador; y por otro, la relativa a las dificultades económicas y sociales encontradas en las zonas donde buscaron refugio, en las que las condiciones de vida fueron precarias o estuvieron marginados de la vida local ${ }^{62}$.

A continuación se exponen dos fotografias sobre familias tarapaqueñas peruanas de los sectores del pueblo de Pica y la localidad de Camiña.

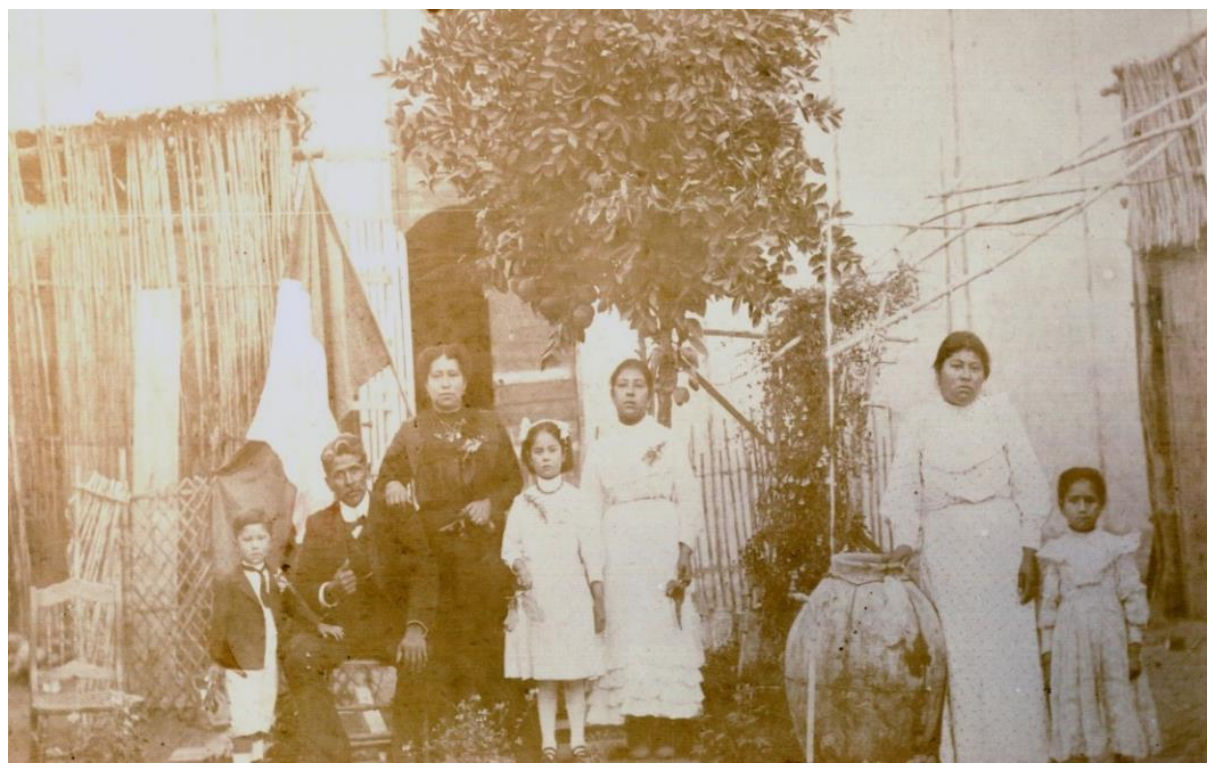

Imagen 2. Familia peruana del poblado de Pica, tras la anexión a Chile de Tarapacá. Fuente: Fotografia cedida por el Sr. Franco Daponte. (Documento de uso público)

61 Documento cedido por la Sra. Elba Brañes.

62 TRONCOSO DE LA FUENTE, R.: "Nación, región e integración...», art. cit., pp. 6-7. 


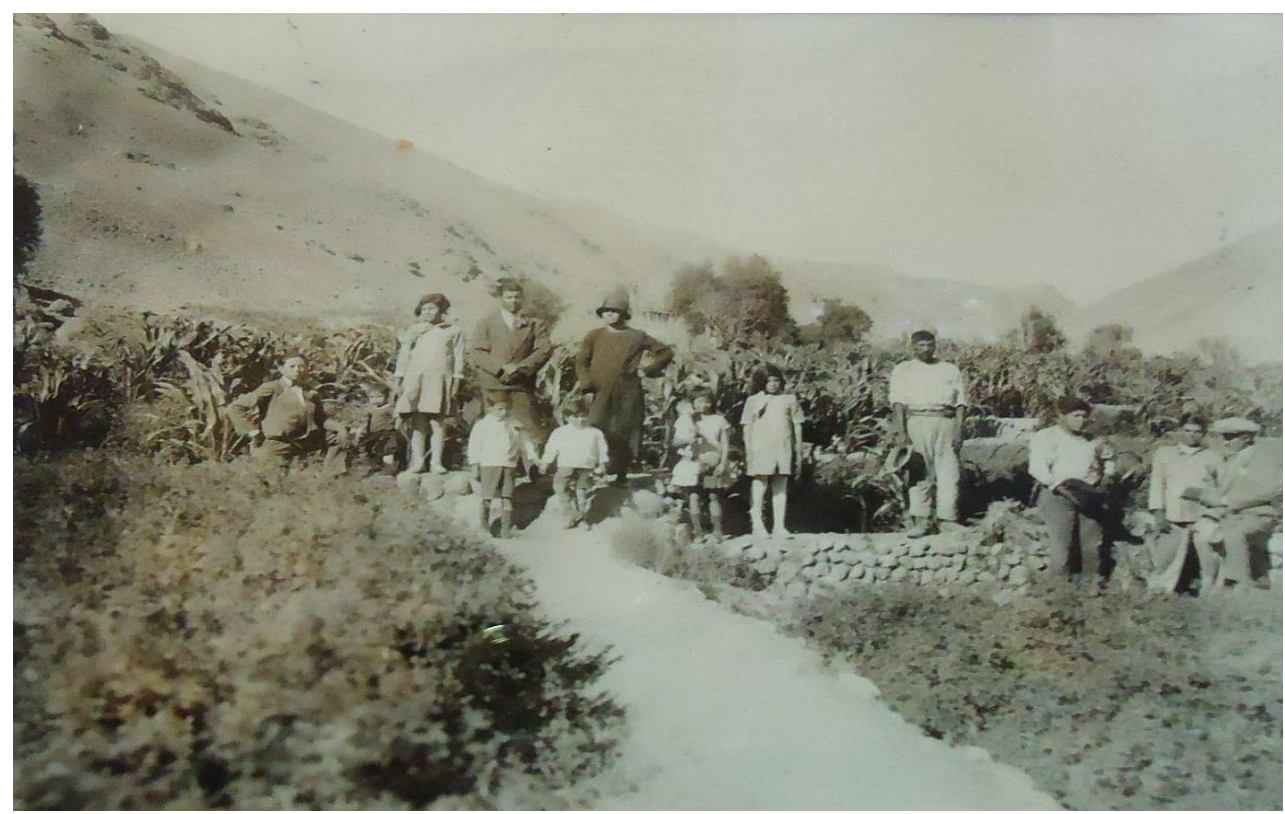

Imagen 3. Familia peruana del poblado de Camiña, después de la anexión a Chile de Tarapacá, relacionada con la Sra. Elvira Brañes, que optó por irse al puerto de Callao, Perú. Fuente: Fotografia cedida por la Sra. Elba Brañes. (Documento de uso público).

En paralelo a los hechos de violencia compulsiva que comenzaban a dar sus frutos, en el sentido de modificar la textura tarapaqueña de una composición cosmopolita y pluriétnica a una uniformada en lo chileno, comenzó o se reactivó la campaña propagandística de agentes chilenos y peruanos buscando favorecer sus intereses territoriales, tanto en el concierto regional-nacional como en el internacional. Sobre el ambiente propagandístico se presenta una carta de la sociedad iquiqueña solicitando a las autoridades que tomaran medidas definitivas sobre el conflicto territorial existente en el norte. El comunicado de 1918 señaló lo siguiente:

El asunto de Tacna y Arica "y Tarapacá", como graciosamente agregan los vecinos del Rimac, cobra por momentos más y más palpitante apariencia, y ante tal evento es ya del caso que nuestro Gobierno muestre un poco más de interés por esta grave cuestión.

Hace dos dias los vecinos de Iquique, en número superior a cinco mil, y acompañados por personas responsables, entre las que se cuentan congresales, altos funcionarios, periodistas, etc., han levantando su voz, en pública reunión, para manifestar el muy justificado deseo de que las autoridades superiores del pais hagan algo en orden a contrarrestar la campaña tendenciosa, unilateral y pasionista que se ha emprendido en el Perú con el ostensible propósito de atraerse el concurso de otras naciones y formarnos a una solución a su tamaño del litigio pendiente.

Lo que ahora pide el pueblo de Iquique lo viene pidiendo nuestro diario desde hace tiempo, y es curioso que en algunos puntos haya entera coincidencia de opiniones, como por ejemplo el de que es necesario abandonar las actitudes indiferentes para atender, por lo menos, a la defensa de nuestros derechos, a nuestra [ilegible] en el extranjero, no 
bastando para el efecto las representaciones oficiales, sino también la acción inteligente de las embajadas, si así pueden llamarse, de profesores universitarios, de escritores, de propagandistas, de miembros de nuestro mundo social y comercial que sean en el exterior, especialmente en Estados Unidos, exponentes de nuestra cultura y de nuestro amor a las más puras libertades democráticas [...]. Si van ya para los nueve años en que un canciller chileno, el señor Edwards, propuso al Gobierno de Lima las bases para llegar a formar el protocolo que habría de establecer, según el Tratado de Ancón, la forma y procedimientos del consiguiente plebiscito, si van ya para los nueve años $y$ aún aquel Gobierno no dice ni chus ni mus al respecto, porque su propósito es, indudablemente, el de no acatar la solución plebiscitaria que se convino en el referido tratado bastaría, a nuestro juicio, una sencilla gestión de parte de Chile, tendiente a dejar en claro una vez más aquella negativa de respuesta para echar por los suelos toda la grita que ante paises extraños han dado ahora en sostener los nerviosos adversarios de otro tiempo. ¿De qué se quejan si no quieren cumplir lo que ellos mismo estipularon?

Es hora ya - repetimos-de que el Gobierno tome algunas posiciones definitivas al respecto ${ }^{63}$.

La propaganda chilena, a través de sus acciones comunicativas, pretendió manifestar a la sociedad nacional e internacional que Perú se abría a una solución plebiscitaria por los territorios en conflicto, y optó por difundir a nivel internacional una campaña tendenciosa, unilateral y apasionada para obtener el concurso de otras naciones en un posible arbitraje o litigio por los territorios en conflicto. En el caso de la propaganda peruana, su empresa se dirigió a alegar en el concierto internacional que los derechos del Perú sobre Tacna, Arica, Tarapacá y Pisagua no podían ser cuestionados porque Chile no quiso y no había querido efectuar el plebiscito contraído con Perú. Sobre el presente tema, el diario El Mercurio de Santiago reprodujo en el mes diciembre de 1918 una nota de La Nación, diario argentino, donde el Sr. M. Porras y el Sr. L. Urieta expusieron sus comentarios. El primero señaló respecto al incumplimiento chileno y la importancia de la Liga de las Naciones para solucionar la cuestión territorial:

Hace 25 años que venció el plazo de ocupación convenido con Chile. Este país no quiso y no ha querido después cumplir el compromiso y efectuar el plebiscito. Si se hubiera efectuado entonces habria triunfado el Perú, y habria recobrado ese territorio [...]. Como viviamos en una época que no existía la Liga de las Naciones ni había una [ilegible] internacional, no quedaba al Perú otro recurso que protestar en medio de la general indiferencia de América debido a la falta de cohesión entre los diferentes componentes.

Hoy las cosas están a punto de cambiar. Puede decirse que, de hecho, están cambiando los problemas internacionales, que no descansan ahora en la eventualidad llamada guerra, sino en las decisiones de

${ }^{63}$ BSS, diario El Mercurio de Valparaíso, p. 3, 4 de noviembre de 1918. 
un tribunal de justicia, al cual ninguna nación puede escapar, salvo que declare a si misma en estado de barbarie.

Chile, a pesar de todos sus esfuerzos, tendrá que inclinarse ante los propósitos del mundo civilizado entero, que formara pacto de la Liga de las Naciones y aceptará sus decisiones ${ }^{64}$.

Aunque las declaraciones cruzadas entre actores chilenos y peruanos pudieron llevar a pensar que el clima sociopolítico pudo pasar en el tiempo de meras opiniones a nuevos hechos de violencia, la situación es que sucedió todo lo contrario. La intención de la diplomacia de ambos países apuntó, después de un largo tiempo, a establecer una propuesta para solucionar los asuntos territoriales que se gatillaron después de guerra del Salitre. Tal es así que, tiempo después los gobiernos de La Moneda en Santiago de Chile y del Palacio Torre-Tagle en Lima (Perú), aceparon la invitación hecha por EE. UU. para finalizar la pugna territorial, trabajo realizado en la ciudad de Washington.

Durante las Conferencias de Washington, celebradas entre el 15 de mayo y 21 de julio de 1922, sobresalieron algunos aspectos relevantes. El primero es que Perú, conocido el acuerdo de que se iban a desarrollar conversaciones entre su nación y Chile para solucionar el problema del norte, activó y promocionó a nivel internacional una narrativa dirigida a exponer las constantes violaciones de las cláusulas del tratado que había hecho Chile, todo ello con el objetivo de señalar que para un adecuado arreglo entre peruanos y chilenos era necesario anular el Tratado de 1883. Entre las violaciones que destacó don Alberto Salomón, ministro de RR. EE. Peruano, se destacaron:

En primer término, Chile ha eludido durante treinta años el cumplimiento de la prescripción del plebiscito que reiteradas veces ha intentado mi pais, como lo prueba toda la documentación diplomática desde 1892, manteniendo, además, la ocupación después de 1894; es decir, después de vencidos los diez años que le acordaba el pacto. Ha expulsado de las provincias cautivas a miles de peruanos, destruyendo sus propiedades; ha clausurado las escuelas que daban alimento espiritual a nuestros niños; ha arrojado a los religiosos peruanos dependientes del obispado de Arequipa [...]; en fin, ha realizado una larga serie de actos injustificables 65.

El segundo aspecto importante de eas conferencias de 1922 es que despertaron la esperanza, tanto de la clase politica peruana como de los tarapaqueños, de que era viable que la comarca del viejo Tarapacá retornaría a Perú. Dicha demanda fue promovida de la siguiente forma por la diplomacia limeña:

Nosotros apelaremos siempre al arbitraje para la revisión completa del Tratado de Ancón. Tarapacá, que antes no hacia parte de nuestro programa, es hoy la primera de nuestras reivindicaciones [...].

Según el derecho internacional americano, que reconoce a cada nación la soberanía y la incolumnidad del respectivo territorio, una república vencedora no puede pedir indemnizaciones territoriales. El

64 BNS, diario El Mercurio de Santiago, p. 15, 17 de diciembre de 1918.

65 BSS, diario El mercurio de Valparaíso, p. 8, 26 de enero 1922. 
postulado de Wilson: "Que el tiempo de las conquistas y el engrandecimiento por medio de ellas ha pasado", y la devolución de las tierras irredentas a los pueblos respectivos como resultado de la guerra de Europa, forman la base de la nueva reivindicación de Tarapacá66.

Fue esa esperanza de regresar a Perú lo que impulsó a un grupo de tarapaqueños a viajar a las conferencias con la intención de tener la posibilidad de plantear su intención de volver a ser parte de la nación peruana. Como es sabido, la participación tarapaqueña en Washington fue menor, y en dichas conferencias fue reafirmada la soberanía chilena sobre Tarapacá, siendo el único tema pendiente sobre chilenos y peruanos la cláusula número tres del Tratado de Ancón.

En cuanto al tercer aspecto referido a Tarapacá y la resolución de las conferencias de 1922, también hay que señalar que si bien estas concluyeron que el territorio dejara de ser objeto de las disputas entre chilenos y peruanos logrando que la violencia patriotera desapareciera sobre los tarapaqueños, pues estos ya no fueron vistos como un problema para el Estado y para la sociedad civil-, igualmente la provincia de Tarapacá siguió estando incluida en el ambiente nacionalista emanado desde Tacna y Arica. La razón de ese proceder fue evitar el asentamiento de población peruana en la región con fines de participar en un posible plebiscito para resolver la situación de Tacna y Arica ${ }^{67}$.

A partir de las conferencias de Washington en 1925 los gobiernos chileno y peruano, con la finalidad de zanjar la soberanía de las cautivas, crearon una comisión plebiscitaria bajo el arbitraje de Estados Unidos. Si bien el objetivo de la comisión designada fue coordinar los preparativos para ejecutar el referéndum, dicha labor - debido a la intensidad de la violencia practicada, particularmente por actores chilenos, en 1925 y 1926 en las zonas de Tacna y Arica - llevó al agente norteamericano a discurrir que era imposible realizar la consulta para decidir qué país debió administrar la soberanía de las cautivas. De ahí que, fracasada la posibilidad de efectuar el plebiscito, las gestiones entre ambos países volvieron a ser reiniciadas en el año 1927, llegando a una propuesta final de resolución del conflicto en el año 1929, en la que fue estipulado que Tacna se reincorporase a Perú y Arica pasase definitivamente al dominio de Chile 68 .

\section{Conclusiones}

Después de la guerra del Salitre, Tarapacá, a pesar de estar cedida legalmente a Chile con el Tratado de Ancón, mantuvo una composición multinacional o cosmopolita y pluriétnica debido a la necesidad de mantener abiertas las fronteras nacionales para el buen funcionamiento de la empresa calichera. Esto produjo que en la comarca tarapaqueña, entre 1883 y 1907, existiera

66 BSS, siario El Mercurio de Valparaiso, p. 3, 29 de abril de 1922.

67 GONZÁLEZ MIRANDA, Sergio: El Dios cautivo. Las ligas patrióticas..., op.cit., pp. 91-101.

68 GONZÁLEZ MIRANDA, Sergio: La llave y el candado La llave y el candado. El conflicto entre Perú y Chile por Tacna y Arica (1883- 1929), Editorial LoM, Chile, 2008. 
una coexistencia pacífica entre chilenos y peruanos. Ejemplo de ello fue que, junto a las actividades e instituciones propias de la vida chilena, funcionaron en Tarapacá periódicos, colegios, bombas y clubes sociales peruanos, además de celebrarse por un lado el 28 de julio el día del Perú en la pampa calichera, $y$, por otro, fiestas locales como La Tirana, celebrada anualmente en forma alternada, ya que el 28 de julio era la fiesta religiosa peruana y el 16 de julio la fiesta pía chilena. Sin embargo, con el correr del tiempo, y especialmente desde 1910, con el centenario de la nación chilena, la coexistencia de lo peruano-chileno - producto de los discursos nacionalistas xenófobos y de los intereses geopoliticos de los grupos de poder asentados en Santiago de Chiley las relaciones peruano-chilenas comenzaron a verse en la ecuación amigoenemigo, y lentamente la población tarapaqueña peruana fue señalada como el principal obstáculo, no solo para la consolidación del proyecto chileno en la región, sino además como el causante de la pauperización y falta de oportunidades de vida para los chilenos en Tarapacá.

Fue un escenario de efervescencia nacional que llevó a emerger las Ligas Patrióticas, que en este segundo período analizado ejercieron su violencia compulsiva contra los peruanos y adheridos a la causa peruana, colaborando sustancialmente en la trasformación de la fisonomía tarapaqueña: de una sociedad pluriétnica, multinacional y de fronteras abiertas a una sociedad homogeneizada y asimilada a los preceptos de la identidad chilena y con fronteras políticas cerradas, dejando en el olvido el pasado peruano de la región de Tarapacá.

Una de las consecuencias trágicas de la actuación de las Ligas Patrióticas fue que una gran parte de tarapaqueños peruanos y trabajadores peruanos asentados en la pampa calichera tuvieran que partir de Tarapacá debido a la violencia nacionalista racista y xenófoba, generando en muchos casos la fragmentación de grupos familiares, el desarraigo territorial y la pérdida en otros de sus trabajos y propiedades que con esfuerzo habian logrado levantar para poseer un mejor futuro.

Para terminar, los sucesos acaecidos en los dos primeros años del período que va desde 1918 a 1922 permiten conjeturar que la consolidación de la nación chilena en Tarapacá fue gracias al papel de las Ligas Patrióticas y su violencia, que en esa coyuntura política fue consentida por el poder político nacional para así eliminar aquellas viejas lealtades y solidaridades con Perú, que estaban obstaculizando la construcción de la nación de Chile en el territorio conquistado con la guerra. 


\section{FUENTES DOCUMENTALES Y BIBLIOGRAFÍA}

\section{Archivos y bibliotecas}

-Archivos Histórico de Santiago.

- Archivo de la Intendencia de Tarapacá de Iquique.

-Biblioteca Nacional de Santiago.

-Biblioteca Santiago Severin de Valparaíso.

\section{Bibliografia}

ALZÁS GARCÍA, Teresa, Luis CASA GARCÍA, Ricardo LUENGO GONZÁLEZ, José TORRES CARVALHO, y Sofia VERÍSSIMO CATARREIRA: "Revisión metodológica de la triangulación como estrategia de investigación", en Revista Investigación Cualitativa en Ciencias Sociales, vol. 3, Portugal, 2016.

BLAIR TRUJILLO, Elsa: "Violencia e identidad", en Revista Estudios Politicos, n. ${ }^{\circ}$ 13, Colombia, 1998.

BASADRE GROHMANN, Jorge: Historia de la República de Perú, Editorial Universitaria, Perú, 1974.

FLORES SORIA, Carlos: "Billinghurst y las salitreras de Tarapacá (18721876)", en Revista Desde el Sur, n. ${ }^{\circ}$ 10, 2008, Perú.

GAVILÁN VEGA, Vivian, y Ana CARRASCO GUTIÉRREZ, Ana: "Festividades Andinas y Religiosidad en el Norte chileno", en Chungará. Revista de Antropología chilena, vol. 41, n. ${ }^{\circ}$, Chile, 2009.

GONZÁLEZ CORTEZ, Héctor, y Vivian GAVILÁN VEGA: "Apuntes sobre el tema de la identidad cultural en la Región de Tarapacá", en Revista Estudios Atacameños, n. ${ }^{\circ}$ 13, Chile, 1997.

GONZÁLEZ MIRANDA, Sergio: "El Estado chileno en Tarapacá: El claroscuro de la modernización, la chilenización y la identidad regional", en Revista Dialogo Andino, n. ${ }^{\circ}$ 13, Chile, 1994.

— "El poder del símbolo en la chilenización de Tarapacá: violencia y nacionalismo entre 1907 y 1950" en Revista de Investigaciones Cientificas y Tecnológicas. Serie Ciencias Sociales, n. ${ }^{\circ}$, Chile, 1995.

- "Tarapacá. El dios cautivo. Reflexiones en torno al regionalismo de los tarapaqueños del Callao", en Revista Debates en Sociología, n. ${ }^{\circ} 22$, Perú, 1997.

— "Tarapacá: Región en conflicto. 1911-1917", en Revista de Investigaciones Científicas y Tecnológicas. Serie Ciencias Sociales, n. ${ }^{\circ}$ 7, Chile, 1997b.

— "VIOLENCIA EN LOS ANDES DE TARAPACÁ: Una reflexión teórica", en Revista Diálogo Andino, n. ${ }^{\circ}$ 20/21, Chile, 2001.

-PAX CASTRENSE EN LA FRONTERA NORTE 1884-1929. El 'Factor Tarapacá' en el conflicto entre Perú y Chile por Tacna y Arica, tesis doctoral en Estudios Americanos, Mención en Relaciones Internacionales, Instituto de Estudios Avanzados (IDEA), Universidad Santiago de Chile, 2003.

- El Dios cautivo. Las Ligas Patrióticas en la chilenización compulsiva de Tarapacá. 1910-1922. Ediciones LoM, Chile, 2004ª. 
- "Pax castrense en la frontera norte. Una reflexión en torno a la post-guerra del Salitre: el conflicto por Tacna-Arica y Tarapacá", en Revista Universum, n. ${ }^{\circ}$ 19, Chile, 2004b.

- La llave y el candado. El conflicto entre Perú y Chile por Tacna y Arica (1883- 1929), Editorial LoM, Chile, 2008.

GONZÁLEZ MIRANDA, Sergio, y Diego LIZAMA GAVILÁN: "El estanco salitrero en Tarapacá y el liberalismo peruano: las influencias "castillista" y "civilista" (1844-1873)", en Revista Aldea Mundo, n. ${ }^{\circ} 48$, Chile, 2019.

GONZÁLEZ MIRANDA, Sergio, Carlos MALDONADO PRIETO, y Sandra MCGEE DEUTSCH: "Las Ligas Patrióticas", en Revista de Investigaciones Científicas y Tecnológicas. Serie Ciencias Sociales, n. ${ }^{\circ}$ 7, Chile, 1993.

GUNDERMANN KRÖLL, H.: "Comunidad, sociedad andina y procesos sociohistóricos en el norte de Chile». Tesis doctoral, Centro de Estudios Sociológicos, Colegio de México, 2001.

- Comunidad indigena y Ciudadanía. La experiencia aymara en el norte de Chile", en Revista Allpanchis, n. ${ }^{\circ}$ 46, Perú, 2005.

NÚÑEZ ATENCIO, Lautaro: "La Tirana del Tamarugal. Del ministerio al sacramento". Antofagasta, Universidad Católica del Norte, Chile, 2004.

- CComentario El Dios Cautivo. Las Ligas Patrióticas en la chilenización compulsiva de Tarapacá (1910-1922)", en Revista Chungara. vol. 37, n. ${ }^{\circ}$ 1, Chile, 2005.

PINTO VALLEJOS, Julio, y Verónica VALDIVIA ORTIZ: Revolución proletaria o querida chusma?: socialismo y Alessandrismo en la pugna por la politización pampina (1911-1932), Ediciones LoM, Chile, 2001.

PINTO VALLEJOS, Julio, Verónica, VALDIVIA ORTIZ, y Pablo ARTAZA BARRIOS: "Patria y Clase en los Albores de la Identidad pampina. 1860-1890", en Revista Historia, vol. 36, Chile, 2003.

TRONCOSO DE LA FUENTE, R.: "Nación, región e integración. El caso de los tarapaqueños peruanos" en Seminario de Historia trinacional Bolivia-ChilePerú, Arica, Chile.

TODOROV, Tzvetan: La conquista de América. El problema del otro, S. XXI, España, 1987.

SOTO LARA, José: "La prensa española como fuente histórica para el problema de Tacna y Arica (1880- 1901): Heurística y método", en Revista de investigación multidisciplinar, n. ${ }^{\circ}$ 7, España, 2014. 